\title{
Introduktion: Politiske rum
}

Emil Husted, ph.d og adjunkt, Institut for Ledelse, Politik og Filosofi, Copenhagen Business School

Andreas Kamstrup, ph.d. og forskningsassistent, Institut for Organisation, Copenhagen Business School

Træd ind i et hvilket som helst indkøbscenter, et hvilken som helst klasselokale, et hvilket som helst fængsel eller et hvilket som helst parlament, og du vil hurtigt opdage, at rumlige konfigurationer er tæt forbundne med politiske idealer. Indkøbscentre er typisk indrettet således, at de afspejler og accentuerer de nyeste tendenser i det omkringliggende forbrugersamfund (Crawford 1992); klasselokalers teaterlignende udformning understøtter generelt et asymmetrisk magtforhold mellem lærer og elev, hvilket besværliggør interaktion og underminerer eventuel modstand overfor underviserens autoritet (McGregor 2004); moderne fængsler er struktureret med udgangspunkt i en disciplinær magtform, der ikke kun søger at straffe men også at normalisere den indsatte (Foucault 1977); og parlamenter er konstrueret $\mathrm{i}$ et forsøg på at organisere og symbolisere den politiske kultur, som de $\mathrm{i}$ sin tid blev bygget for at institutionalisere (Goodsell 1988). På den måde synes det, som flere af artiklerne i dette temanummer ligeledes påpeger, forholdsvist ukontroversielt at hævde, at rum er politiske.

Trods dette bliver rum eller rumlighed hyppigt konceptualiseret som en mere eller mindre apolitisk størrelse. Som den britiske geograf, Doreen Massey (1992; 2005), gentagende gange har fremhævet, anskues rum i socialvidenskaben ofte som det diametralt modsatte af tid, hvilket ikke blot strider imod Einsteins relativitetsteori, men også giver rum (space på engelsk) en relativt statisk karakter. Et eksempel på denne tendens kan findes i den argentinske politiske teoretiker, Ernesto Laclaus, post-strukturalistiske diskursteori. I et forsøg på at udvikle et nyt vokabular til den akademiske venstrefløj positionerer Laclau (1990) netop den rumlige dimension som det eksakt modsatte af den tidslige dimension; og mens 'det temporale' for Laclau udgør selve mediet for politik - forandringer sker altid i tid - repræsenterer 'det spatiale' en eliminering af politikkens mulighedsrum. Som han skriver i en kendt passage: 'Politics and space are antinomic terms. Politics only exists insofar as the spatial eludes us' (Laclau 1990, 68).

Selvom flere diskursteoretikere sidenhen har forsvaret Laclaus teori med, at det spatiale skal forstås på et mere symbolsk plan som en generel betegnelse for fiksering af kontingens og ikke nødvendigvis som noget, der refererer til fysiske rum (f.eks. Howarth 2006), har sådanne begrebsliggørelser ikke desto mindre bidraget til en afpolitisering af rumlighed som empirisk fænomen. Modsat denne udvikling står den klassiske marxisme, 
der siden begyndelsen har tematiseret materialitet (hvilket må siges at være en væsentlig komponent i de fleste rum) som en afgørende faktor i politiske kampe. En grundfigur hos Marx (1939) er det dyadiske forhold mellem overbygning og basis, hvor førstnævnte kategori indeholder begreber som kunst, familie, politik, videnskab og kultur, mens sidstnævnte repræsenterer de konkrete produktionsmidler (f.eks. værktøjer, maskiner, land etc.). I påvirkningen mellem disse to kategorier giver Marx basis forrang, således at superstrukturer primært vedligeholder basis, hvorimod basis aktivt former superstrukturer. Dette er grunden til, at Marx ofte betegnes som materialist.

En lignende tematisering af forholdet mellem materialitet og politik finder man inden for organisationsteorien i den såkaldte 'labor process theory', der ofte associeres med Harry Braverman (1974) og senere Michael Burawoy (1979). Førstnævnte så eksempelvis introduktionen af automatiseret produktionsteknologi i starten af det tyvende århundredes som en accentuering af arbejderens udbytning og fremmedgørelse, i den forstand at sådanne teknologier (f.eks. samlebånd) fravristede arbejderen den sidste rest af kontrol over arbejdets formelle organisering (se også Blauner 1964). På samme måde synes det heller ikke helt tilfældigt, at nogle af de mest kendte teoretiseringer af forholdet mellem politik og rum - f.eks. Henri Lefebvres (1991) klassiske distinktion mellem 'perceived space', 'conceived space' og 'lived space' eller Manuel Castells (1996) idé om 'space of flows' - kommer ud af netop den marxistiske tradition

Med den klassiske marxismes faldende popularitet fra starten af 1970'erne og frem er det kritiske blik på rummets politiske dimension dog langsomt gledet i baggrunden. Ikke blot har interessen for arkitektur, indretning og materialitet indtil for nylig været faldende på tværs af flere discipliner, forskere har generelt set også manglet et vokabular til at beskrive disse faktorer i relation til politik (Husted og Plesner 2017). Med dette temanummer forsøger vi at tage et skridt på vej mod at udbedre begge disse mangler. For det første giver temanummerets fem artikler forskellige bud på, hvilke typer af rum, der kan analyseres, og hvorledes disse kan beskrives politisk. For det andet leverer flere af artiklerne konkrete bud på koncepter og analysestrategier, der kan hjælpe forskere og studerende med interesse for politiske rum til at foretage deres egne undersøgelser. Som redaktører er det særligt sidstnævnte, der er vores mål - at stimulere vedvarende diskussion og analyse af relationen mellem rum og politik.

\section{Temanummerets artikler}

Temanummeret indeholder som nævnt fem artikler, der alle belyser relationen mellem rum og politik på forskellige måder. Artiklerne er placeret i en rækkefølge, hvor de første er relativt teoretiske, mens de sidste er overvejende empiriske. Trods dette indeholder alle bidragene dog empiriske cases eller illustrative eksempler, der kan give læseren inspiration til at foretage sine egne undersøgelser af politiske rum. På samme måde opererer samtlige artikler med en mere eller mindre ekspliciteret analysestrategi, der viser hvorledes rummets politiske dimension kan belyses og forstås fra forskellige vinkler. Samlet set 
giver temanummeret altså en bred forståelse for, hvorledes socialvidenskaben kan modarbejde devisen om, at rum og materialitet per definition er neutrale eller apolitiske størrelser.

I den første artikel udfolder Lydia Jørgensen og Christian Borch en eklektisk samtænkning af teorier udarbejdet af de to tyske fænomenologer, Gernot Böhme og Peter Sloterdijk. Centralt i artiklen står de to filosoffers (atmo)sfære-begreber, der bringes i dialog for netop at vise, hvordan arkitektur kan siges at have en politisk dimension. Jørgensen og Borch starter med at introducere en distinktion mellem Politik og politik; mens førstnævnte betegner 'et generelt ekspressivt lag, som skal repræsentere eller understøtte en bestemt politisk identitet', refererer sidstnævnte til 'hverdagslige forsøg på at regulere adfærd' (Jørgensen og Borch 2018, 7-8). Modsat mange andre studier af politisk arkitektur, beskæftiger artiklen sig med lille-p-politik, hvilket dog ikke er tekstens eneste forskningsmæssige bidrag. Udover at levere en overbevisende kombination af Böhme og Sloterdijks vokabularer, diskuterer artiklen nemlig også arkitekturens (eller rettere æstetikkens) kritiske potentiale. Mens Böhmes brug af atmosfære-begrebet har et klassisk emancipatorisk sigte, hvormed kritik handler om at frigøre mennesket fra arkitekturens repressive strukturer, anlægger Sloterdijk et genealogisk perspektiv, der tjener til at synliggøre arkitekturens kontingente karakter.

I temanummerets anden artikel tager Thorben Simonsen og Holger Højlund over, hvor den første artikel slap, ved at vise hvordan Sloterdijks vokabular kan anvendes empirisk til at analysere politiske rum. Artiklens empiriske case er Danske Regioners nye supersygehus i Slagelse, hvilket forfatterne hævder manifesterer et eksempel på 'helende arkitektur', hvor de enkelte rum ikke blot understøtter patienternes sårbarhed, men samtidig skubber dem på vej mod helbredelse. Modsat den første artikel er det særligt Sloterdijks explikations-begreb, der her bringes i spil for at vise, hvordan udvalgte elementer af den helende arkitektur flugter med en et politisk ideal om progression og udvikling. En hovedpointe $\mathrm{i}$ artiklen er dog, at rummenes arkitektoniske explikationer ikke fuldt ud determinerer patienternes handlerum. Patienterne har nemlig mulighed for at modsætte sig de politiske forventninger om hurtig 'recovery' ved eksempelvis at skabe personlige rum, der midlertidigt isolerer dem fra den socialitet, som sygehuset repræsenterer. Forfatternes udtryk for dette møde mellem politiske idealer og lokal praksis er 'rummets grammatik'. Som Simonsen og Højlund $(2018,39)$ skriver:

"Et rum aflæses, fortolkes og udfordres i praksis. Det defineres ikke alene af dets skabere, men ligeledes af de sociale sammenhænge og praksisser, hvorigennem mennesker giver indhold til de rum, de indtræder i. Derfor vil mere etnografisk orienterede analyser fremover kunne bidrage til bedre at forstå de faktiske livsformer og praksisser, som opstår i og udfordrer et rums grammatik."

I temanummerets tredje artikel, skrevet af Rune Thorbjørn Clausen og Kasper Trolle Elmholdt, er der ligeledes forhandling på spil. Her er det dog ikke Sloterdijks fænomenologi, 
der fungerer som teoretisk afsæt, men snarere Michel de Certeaus 'tactic'-begreb. Forfatterne anvender dette til at vise, hvordan ansatte i mediekoncernen $A M$ på kreativ vis modsætter sig ledelsens ambitioner om at skabe et ekstraordinært åbent arbejdsmiljø, understøttet af glas-baseret arkitektur og fleksible kontorlandskaber, ved eksempelvis at benytte paraplyer til at skabe et personligt rum med begrænset lysindfald. Baseret på sådanne observationer viser forfatterne, hvordan rumlige konfigurationer altid er et resultat af 'settlement' i ordets dobbelte betydning, forstået som det at bebo et givent rum og samtidig indgå forlig vedrørende dets konfiguration. Ligesom den foregående artikel afsluttes også denne med en diskussion af vigtigheden af at studere 'micropolitics in action' (Clausen og Elmholdt 2018, 57), og hvordan enhver arkitektonisk struktur eller rumlig indretning altid trækker en konstitutiv grænse, der inkluderer visse identiteter og ekskluderer andre.

Hvor artiklerne ovenfor har som ambition at skrive det politiske frem i det, der ellers let kunne forsvinde i hverdagens repetitivitet, søger Signe Wehl (2018) i temanummerets fjerde artikel at vise, hvordan et konkret rum gennem kunstneriske og arkitektoniske greb får en kritisk-politisk stemme. Casen er Trampolinhuset i København, der oprindeligt blev søsat som en kritik af rammerne for asylansøgere, men samtidig også som et frirum for disse mennesker. På trods af den systemkritiske modus er det lykkedes huset at opnå støtte og opbakning fra mange eksterne partnere, herunder kommunale og statslige instanser, og gennem først en fyldestgørende empirisk indføring i de særlige omstændigheder omkring Trampolinhuset og dernæst en essayistisk diskussion af rummets mulighed for at bedrive politik som moddiskurs, nuancerer artiklen forholdet mellem rum, kunst og politik. Bidraget trækker i høj grad på Jane Rendells (2006) kritiske konceptualiseringer af æstetiske virkemidlers politiske potentiale, men derudover diskuteres der også ud fra bl.a. Chantal Mouffe (2013), Ole B. Jensen (2004) og Claire Bishop (2006).

I temanummerets sidste artikel løfter Jonathan Schmidt (2018) os op på et mere samfundsmæssigt niveau ved at diskutere fondes rolle i konstruktionen af såkaldte 'crosssector collaborative spaces'. Artiklen fremhæver, at innovations-litteraturen er splittet i forhold til spørgsmålet om, hvilken af samfundets tre sektorer, der er bedst positioneret til at skabe rum for samarbejde på tværs af sektorerne i forhold til vor tids største udfordringer (f.eks. klimaforandringerne). Med afsæt i en abduktiv forskningsstrategi undersøger Schmidt et konkret eksempel på dette, nemlig BLOXHUB i København, som primært er finansieret af Realdania $\mathrm{i}$ et forsøg på at adressere udfordringer relateret til bæredygtig byudvikling. Konklusionen på denne undersøgelse er, at Realdanias rolle som den absolut mest dedikerede aktør i samarbejdet har tilladt en form for 'non-commitment' blandt aktørerne i den offentlige sektor, hvilket på sigt kan risikere at underminere BLOXHUB-projektets evne til at udvikle innovative løsninger på samfundsmæssige problemer.

Selvom de fem artikler således undersøger vidt forskellige fænomener igennem vidt forskellige begreber, synes nogle pointer dog at gå igen. For det første fremhæver størstedelen af artiklerne vigtigheden af at studere det, som Jørgensen og Borch i deres 
artikel kalder politik (i modsætning til Politik). I stedet for kun at fokusere på spektakulære bygningsværker og deres eksplicit politiske symbolik, handler det med andre ord om at udvikle en følsomhed over for de mondæne og ofte implicitte måder, hvorpå rum regulerer menneskelig adfærd. En anden fælles konklusion synes at være, at denne form for hverdags-politik bedst studeres igennem etnografiske metoder, da disse tillader forskeren at dykke ned i praksis og at mærke rummets politik på egen krop. En tredje konklusion, der går på tværs af de fleste artikler, er, at rum ikke kan designes således, at de entydigt determinerer beboernes adfærd eller deres egen betydning. Ingen rummelighed er totalitær. Politiske rum levner altid plads til forhandling, modstand, subjektivitet og frihed.

Således opmuntret er der kun tilbage at sige: God læselyst.

\section{Litteratur}

Bishop, C. (2006). The social turn: Collaboration and its discontents. New York, NY: Art Forum.

Blauner, R. (1964). Alienation and freedom: The factory worker and his industry. Chicago, IL: University of Chicago Press.

Braverman, H. (1974). Labor and monopoly capital: The degradation of work in the twentieth century. New York, NY: Monthly Review Press.

Burawoy, M. (1979). Manufacturing consent: Changes in the labor process under monopoly capitalism. Chicago, IL: The University of Chicago Press.

Castells, M. (1996). The rise of the network society. Oxford: Blackwell Publishers.

Clausen, R. T. \& Elmholdt, K. T. (2018). Making room for change: Spatial tactics and the micropolitics of inhabiting organizational space. Politik, årg. 21(2), s. 43-61.

Crawford, M. (2000). The world in a shopping mall. I: M. Miles, T. Hall, \& I. Borden (eds.), The city cultures reader. London: Routledge, s. 124-140.

Foucault, M. (1977). Discipline and Punish: The Birth of the Prison. New York, NY: Pantheon.

Goodsell, C. T. (1988). The Architecture of Parliaments: Legislative Houses and Political Culture. British Journal of Political Science, årg. 18(3), s. 287-302.

Howarth, D. (2006). Space, Subjectivity, and Politics. Alternatives: Global, Local, Political, årg. 31(2), s. 105-134.

Husted, E., \& Plesner, U. (2017). Spaces of open-source politics: Physical and digital conditions for political organization. Organization, årg. 24(5), s. 648-670.

Jensen, O. B. (2006). Byen, magten og netværket: en ny bysociologis læsninger af de urbane interventioners repræsentationelle logik. Dansk Sociologi, årg. 15(3), s. $49-65$.

Jørgensen, L. \& Borch, C. (2018). Arkitektur og politik: Atmosfæriske refleksioner ud fra Böhme og Sloterdijk. Politik, årg. 21(2), s. 7-21.

Laclau, E. (1990). New reflections on the revolution of our time. New York, NY: Verso. 
Lefebvre, H. (1991). The Production of Space. Oxford: Blackwell Publishing.

Marx, K. (1939). Grundrisse: Foundations of the critique of political economy. London: Penguin Books.

Massey, D. (2005). For space. London: SAGE.

Massey, D. (1992). Politics and time/space. New Left Review, årg. 196, s. 65-84.

McGregor, J. (2004). Space, power and the classroom. Forum, årg. 46(1), s. 13-18.

Mouffe, C. (2013). Agonistics: Thinking the world politically. London: Verso.

Rendell, J. (2006). Art and architecture: A place between. London: I.B. Tauris.

Simonsen, T. \& Højlund, H. (2018). Rummets grammatik: Helende arkitektur i psykiatrien. Politik, årg. 21(2), s. 22-42.

Schmidt, J. (2018). Commitment to non-commitment: The role of a foundation in configuring a cross-sector collaborative space. Politik, årg. 21(2), s. 76-93.

Wehl, S. B. (2018). Trampolinhuset: Kulturelt rum som politisk modspil. Politik, årg. $21(2)$, s. $62-75$. 